\title{
Sensor-augmented pump and Down syndrome: a new tool in tricky patients
}

\author{
Response to "Specific use of CSIl during enteral \\ nocturnal nutrition in a child with type 1 diabetes, \\ Hashimoto's thyroiditis, and Down syndrome"
}

Andrea E. Scaramuzza', Valentina Comaschi', Matteo Ferrari', Gian Vincenzo Zuccotti ${ }^{1}$

$\mathrm{W}$ e read with great interest the paper by Piccini and cols. (1) published in the July issue of this Journal.

Some years ago, we published the first report ever (to the best of our knowledge) of successful treatment of a girl with Down syndrome, Hashimoto's thyroiditis and celiac disease with continuous subcutaneous insulin infusion (2). Since then, her glycemic control was kept constant and, most of the time, in the target range (HbAlc in 2009: $7.75 \pm 0.21 \%$; HbAlc in 2010: $7.35 \pm 0.19 \%$; HbAlc in 2011: $7.42 \pm 0.30 \%$ ).

At the end of 2011 , sensor-augmented pump was initiated (Animas ${ }^{\circledR}$ Vibe $^{\mathrm{TM}}$, West Chester, PA, USA) because of both a quite high glycemic variability and the parents' request, and her HbAlc kept improving (HbAlc in 2012: $7.30 \pm 0.20 \%$; Halc in 2013: $7.10 \pm 0.28 \%)$.

CSII has been recognized as effective and safe in pediatric (3) and in adult patients (4), not only in the short run, but even after many years (5). In patients with Down syndrome and type 1 diabetes, glycemic control may sometimes be particularly tricky $(6,7)$.

In our patient, as well as in the one of Piccini and cols. (1), CSII was a safe and effective way to manage diabetes.

For a successful CSII therapy in a patient with Down syndrome, whose mental function may be impaired, the collaboration of a highly motivated and compliant family is essential, as well as a skilled multidisciplinary diabetes team (8). Given all of this, pump increased the patient's and family's flexibility, as we had previously reported (2).

The significant improvement in the glycemic control observed, and the high level of acceptance of CSII therapy observed in both our case and in that of Piccini and cols. is worth the effort of the patient's family and of the diabetes team in ensuring that the patient has a flexible life.

Perhaps CSII therapy might be taken into account when considering insulin therapy in patients with Down's syndrome.

Disclosure: no potential conflict of interest relevant to this article was reported.

\section{REFERENCES}

1. Piccini B, Toni S, Lenzi L, Barni F, Guasti M, Belli F, et al. Specific use of CSIl during enteral nocturnal nutrition in a child with type 1 diabetes, Hashimoto's thyroiditis, and Down syndrome. Arq Bras Endocrinol Metabol. 2013;57:388-92.

2. Scaramuzza AE, Giani E, Riboni S, Spiri D, De Palma A, Mameli C, et al. Insulin pump therapy for type 1 diabetes treatment in a girl with Down's syndrome. Diabetes Res Clin Pract. 2009;85:e16-8.
Department of Pediatrics, Pediatric Diabetology Unit, University of Milano, 'Luigi Sacco' Hospital, via Giovanni Battista Grassi, Milano, Italy

Correspondence to:

Andrea E. Scaramuzza

Clinica Pediatrica

Azienda Ospedaliera, Università di

Milano, "Ospedale Luigi Sacco"

Via G. B. Grassi, 74

20157 - Milan, Italy

scaramuzza.andrea@hsacco.it

Received on Ago/20/2013 Accepted on Jan/24/2014

DOI: 10.1590/0004-2730000002948 
3. Misso ML, Egberts KJ, Page M, O'Connor D, Shaw J. Continuous subcutaneous insulin infusion (CSII) versus multiple insulin injections for type 1 diabetes mellitus. Cochrane Database Syst Rev. 2010;(1):CD005103.

4. Monami M, Lamanna C, Marchionni N, Mannucci E. Continuous subcutaneous insulin infusion versus multiple daily insulin injections in type 1 diabetes: a meta-analysis. Acta Diabetol. 2010;47(suppl 1):77-81.

5. Mameli C, Scaramuzza AE, Ho J, Cardona-Hernandez R, Suarez-Ortega L, Zuccotti GV. A 7-year follow-up retrospective, international, multicenter study of insulin pump therapy in children and adolescents with type 1 diabetes. Acta Diabetol. 2014;51(2):205-10.

6. Kinik ST, Ozcay F, Varan B. Type I diabetes mellitus Hashimoto's thyroiditis and celiac disease in an adolescent with Down syndrome. Pediatr Int. 2006;48:433-5.

7. Lammer C, Weimann E. Early onset of type I diabetes mellitus, Hashimoto's thyroiditis and celiac disease in a 7-yr-old boy with Down's syndrome. Pediatr Diabetes. 2008;9(4 Pt 2):423-5.

8. Pinelli L, Rabbone I, Salardi S, Toni S, Scaramuzza A, Bonfanti R, et al. Insulin pump therapy in children and adolescents with type 1 diabetes: the Italian viewpoint. Acta Biomed. 2008;79:57-64. 